I N F ORM A T I R

Jurnal Informatika, Manajemen dan Komputer, Vol. 10, No.1 , MEl 2018

eISSN : 2580 - 3042

pISSN : $1979-0694$

\title{
PROTOTYPE LEMARI PENGERING PAKAIAN OTOMATIS
}

\author{
Rosmanila $^{1}$, Teuku Radillah ${ }^{2}$, Amat Sofiyan ${ }^{3}$ \\ ${ }^{1,2,3}$ Sekolah Tinggi Manajemen Informatika Dan Komputer (STMIK DUMAI) \\ JL.Utama Karya Bukit Batrem, Kota Dumai - Riau \\ e-mail :rosmanila01041994@gmail.com
}

\begin{abstract}
ABSTRAK
Pemanasan Global yang menyebabkan perubahan cuaca yang tidak menentu. Perubahan cuaca yang tidak menetukan ini yang menyebabkan kerepotan jika hujan turun menerus, sehingga pakaian yang sudah di cuci tidak bisa kering. Karena hal inilah yang memunculkan ide untuk menciptakan alat pengering pakaian otomatis. Mikrokontroler ATMega328 digunakan sebagai pengontrol dalam proses pengeringan secara elektronik. Hal ini lebih mudah untuk mengeringkan pakaian tanpa harus menunggu cuaca cerah. Sensor suhu dan kelembaban DHT-11 digunakan sebagai pendeteksi suhu didalam ruangan pengeringan pakaian. Lampu bholam yang digunakan sebagai komponen pengering dan kipas fan digunakan untuk menyebarkan panas dalam ruangan pengeringan pakaian. Sedangkan Arduino Uno sebagai software untuk mengontrol Mikrokontroler ATMega328. Hasil penelitian menunjukkan bahwa alat mampu mengeringkan lpakaian dengan jumlah waktu 17 menit dan panas matahari memerlukan waktu 1 jam 5 menit. Jadi jarak waktu pengeringan otomatis dengan panas matahari sekitar 1 jam. Dengan demikian alat pengering pakaian ini dapat di gunakan sebagai pengganti sinar matahari jika cuaca hujan.
\end{abstract}

Kata kunci : prototype,mikrokontroler ATMega32,lemari Pengering, pengering otomatis

\section{PENDAHULUAN}

Pengeringan pakaian merupakan kegiatan yang biasa dilakukan sehari-hari yang memanfaatkan energi panas matahari untuk proses penguapan kandungan air pada pakaian selang waktu tertentu sampai pakaian dapat dikatakan kering dan siap untuk digunakan. Hampir seluruh masyarakat Indonesia mengandalkan energi panas matahari untuk proses pengeringan pakaian. Meskipun demikian, proses pengeringan dengan energi matahari tetap memiliki kekurangan. Kondisi cuaca yang tidak menentu seperti turunnya hujan secara tiba-tiba membuat proses pengeringan dengan energi matahari tidak dapat dilakukan kapan saja.

Pemanasan global (global warming) yang merupakan salah satu fenomena meningkatnya suhu bumi yang disebabkan oleh meningkatnya emisi gas-gas seperti $\mathrm{CO} 2, \mathrm{CH} 2, \mathrm{~N} 2 \mathrm{O}$ dan (Eka Lestari Kaloko, 2016). Hal membuat kondisi cuaca sudah tidak dapat diprediksi lagi. Oleh karena itu aktivitas manusia untuk mengeringkan pakaian cukup terganggu dan menjadi sangat merepotkan apabila pakaian yang telah dicuci tidak kering selama berharihari sehingga tidak dapat dipergunakan, selain itu kondisi tempat atau lokasi yang tersedia sempit juga menjadi kendala lain karena proses pengeringan pakaian menggunakan energi matahari membutuhkan tempat atau lokasi yang luas, serta sering terjadi kehilangan pakaian ketika pakaian dikeringkan di luar rumah menjadi sebuah kekhawatiran tersendiri bagi pemilik pakaian untuk mengeringkan pakaiannya.

Untuk mengatasi permasalahan tersebut maka perlu adanya suatu perangkat yang dapat mengeringkan pakaian kapan saja, tidak membutuhkan waktu yang lama dalam proses pengeringan, tempat atau lokasi yang luas dan juga tidak tergantung dengan kondisi cuaca serta menghilangkan kehawatiaran kehilangan pakaian bagi pemilik pakaian untuk mengeringkan pakaiannya. Salah satu solusi untuk mengatasi permasalahan tersebut adalah dengan memanfaatkan teknologi Mikrokontroler Arduino Uno R3 sebagai pengendali utama, sensor suhu dan kelembaban DHT-11, LCD Display Character 16 x 2, Relay 
IN F O R M A I I A

Jurnal Informatika, Manajemen dan Komputer, Vol. 10, No.1 , MEl 2018

eISSN : 2580 - 3042

pISSN : $1979-0694$

serta Motor DC dan lampu bohlam yang dirangkai sedemikian rupa menjadi sebuah perangkat pengering pakaian yang dapat mengeringkan pakaian secara otomatis tanpa membutuhkan waktu yang lama dan tempat atau lokasi yang luas serta tidak tergantung dengan kondisi cuaca.

Adapun tujuan penelitian ini adalah :

1. Merancang perangkat lemari pengering pakaian berbasis mikrokontroler ATMega328 yang dapat mengeringkan pakaian tanpa memakan banyak waktu dan tempat.

2. Mengurangi ketergantungan terhadap panas matahari dalam proses pengeringan pakaian.

3. Mempersingkat waktu pengeringan pakaian, dengan adanya prototype ini.

4. Mengetahui perbandingan kecepatan proses pengeringan menggunakan prototype pengering pakaian yang dibuat dengan berbagai variasi jumlah pakaian dan kondisi awal pakaian yang akan dikeringkan.

\section{a. Sistem}

Sistem adalah kumpulan dari elemenelemen yang berintekrasi untuk mencapai suatu tujuan tertentu. Kedua kelompok definisi tersebut adalah benar dan tidak bertentangan, yang bebeda adalah cara pendekatannya. Pendekatan sistem yang merupakan kumpulan elemen-elemen atau komponen-komponen atau subsistem-subsistem merupakan definisi yang lebih luas. Definisi ini lebih banyak diterima, karena kenyataannya suatu sistem dapat terdiri dari beberapa subsistem atau sistem bagian.(Kusbianto, 2010)

\section{b. Sejarah $\mathrm{C}++$}

Pada mulanya bahasa komputer digunakan untuk membantu dalam melakukan perhitunganperhitungan telemetri. Ketika itu, bahasa yang digunakan masih primitive sekali karena masih beupa bahasa mesin yang hanya mengenal angka 1 dan 0 . Selanjutnya bahasa mesin tersebut disederhanakan menjadi bahasa yang agak dipahami dengan menghadirkan statemenstatemen khusus yang disebut dengan istilah mnemonic seperti $A A D, M O V, J M P$ dan yang lainnya. Bahasa ini disebut dengan bahasa Assembly yang masih termasuk ke dalam bahasa tingkat rendah (low level language).

Tahun 1969, laboraturium Bell AT\&T di Muray Hill, New Jersey menggunakan bahasa Assembly ini untuk mengembangkan sistem operasi UNIX. Maksudnya adalah untuk membuat sistem operasi yang dapat bersifat "programmer-friendly". Setelah UNIX berjalan, Ken Thompson, seorang pengembang sistem di laboraturium tersebut mengembangkan compiler baru dengan nama bahasa B. bahasa B ini masih bersifat interpret dan lambat, maka pada tahun 1971, sistem operasi UNIX kemudian ditulis ulang dengan menggunakan bahasa $\mathrm{C}$, yaitu bahasa pemrograman yang dikembangkan oleh Dennis Ritchie, seorang pengembang sistem di laboratorium yang sama. Namun sayangnya bahasa $\mathrm{C}$ merupakan bahasa yang masih tergolong susah untuk dipelajari karena masih bersifat procedural murni. Untuk membentuk satu objek, kita harus melakukan banyak sekali penulisan kode. Hal ini tentu akan dikatakan sebagai sebuah kelemahan. Pada tahun 1983, seorang doktor bernama Bjarne Stroustrup yang saat itu juga bekerja di laboratorium yang sama menciptakan bahasa baru yaitu bahasa $\mathrm{C}++$ yang merupakan bahasa turunan dari bahasa $\mathrm{C}$. Bahasa Tingkat Tinggi (Modula-2,Pascal,Cobol,Fortran,Basic) Bahasa Tingkat Menengah (Java, C++,C, Forth) Bahasa Tingkat Rendah (Macro-Assembler, Assembler). Menurut Bjarne Stroustrup (pencipta $\mathrm{C}++$ ), alasan mengapa $\mathrm{C}$ diambil sebagai bahasa dasar dari pembentukan bahasa $\mathrm{C}++$ adalah dapat dihubungkan dengan bahasa tingkat rendah, berjalan di manapun dan untuk masalah apa pun, berjalan mulus dalam system operasi unix.(Raharjo, 2013)

\section{c. Arduiono}

Arduiono adalah kit elektronik atau papan rangkaian elektronik open source yang didalamnya terdapat komponen utama, yaitu sebuah chip mikrokontroller dengan jenis AVR dari perusahaan Atmel. Mikrokontroller itu sendiri adalah chip atau IC (integrated circuit) yang biasa di program dengan komputer tujuan menanamkan program pada mikrikontroler adalah agar rangkaian elektronik dapat membaca input, memproses input tersebut dan kemudian menghasilkan output sesuai yang diinginkan.(Syahwil, 2013)

\section{d. Pengertian Flowchart}

Flowchart dalam bahasa Indonesia diterjemahkan sebagai Diagram Alir. Dari dua kata ini, maka dapat kita bayangkan bahwa 
IN F ORM T I K

Jurnal Informatika, Manajemen dan Komputer, Vol. 10, No.1 , MEI 2018

elSSN : $2580-3042$

pISSN : $1979-0694$

flowchart itu terbentuk diagram yang bentuknya dapat mengalirkan sesuatu. Contoh sederhananya adalah masalah membuat secangkir kopi. Dalam membuat secangkir kopi, tentu saja diperlukan langkah - langkah yang berurutan agar hasilnya dapat sesuai dengan apa yang kita inginkan, yaitu secangkir kopi. Demikian halnya dalam memprogram, diperlukan suatu algoritma (urutan langkahlangkah logis penyelesaian masalah yang disusun secara sistematis) agar program kita buat dapat berjalan dan memberikan hasilnya valid untuk merepresentasikan algoritma itulah kita gunakan flowchart.(Kurniadi, 2011)

Tabel 1 Simbol Flowchart Program

\begin{tabular}{|c|c|c|c|}
\hline No & $\begin{array}{l}\text { Gambar } \\
\text { Simbol }\end{array}$ & $\begin{array}{l}\text { Nama } \\
\text { Simbol }\end{array}$ & Fungsi \\
\hline 1 & & $\begin{array}{l}\text { Termina } \\
l\end{array}$ & $\begin{array}{l}\text { Mengawali atau } \\
\text { mengakhiri } \\
\text { instruksi yang } \\
\text { akan digunakan }\end{array}$ \\
\hline 2 & & $\begin{array}{l}\text { Prepara } \\
\text { tion }\end{array}$ & \begin{tabular}{l}
\multicolumn{2}{l}{ Menunjukkan } \\
harga awal atau \\
pemberian nilai \\
inisialisasi
\end{tabular} \\
\hline 3 & & $\begin{array}{l}\text { Input / } \\
\text { Output }\end{array}$ & $\begin{array}{ll}\text { Membaca } & \text { atau } \\
\text { menulis data } & \text { atau } \\
\text { informasi } & \text { oleh } \\
\text { computer } & \end{array}$ \\
\hline 4 & & Process & $\begin{array}{l}\text { Melakukan proses } \\
\text { baik berupa } \\
\text { perhitungan atau } \\
\text { perubahan harga } \\
\text { variable }\end{array}$ \\
\hline 5 & & $\begin{array}{l}\text { Decisio } \\
n\end{array}$ & $\begin{array}{l}\text { Menentukan } \\
\text { proses mana yang } \\
\text { akan diambil dari } \\
\text { dua proses yang } \\
\text { berbeda, } \\
\text { berdasarkan suatu } \\
\text { kondisi yang } \\
\text { diajukan }\end{array}$ \\
\hline 6 & & $\begin{array}{l}\text { Predefin } \\
\text { ed }\end{array}$ & $\begin{array}{l}\text { Memanggil suatu } \\
\text { sub program }\end{array}$ \\
\hline 7 & & $\begin{array}{l}\text { Connect } \\
\text { or }\end{array}$ & \begin{tabular}{lr}
\multicolumn{2}{l}{ Menghubungkan } \\
urutan & proses \\
yang & terputus \\
dalam & satu \\
halaman & \\
\end{tabular} \\
\hline 8 & & $\begin{array}{l}\text { Off } \\
\text { Page }\end{array}$ & $\begin{array}{l}\text { Menghubungakan } \\
\text { urutan proses }\end{array}$ \\
\hline
\end{tabular}

\begin{tabular}{|l|l|l|l|}
\hline No & $\begin{array}{l}\text { Gambar } \\
\text { Simbol }\end{array}$ & $\begin{array}{l}\text { Nama } \\
\text { Simbol }\end{array}$ & Fungsi \\
\hline & & $\begin{array}{l}\text { yang terputus } \\
\text { dalam satu } \\
\text { halaman yang } \\
\text { berbeda }\end{array}$ \\
\hline 9 & $\longrightarrow$ & $\begin{array}{l}\text { Flow } \\
\text { Line }\end{array}$ & $\begin{array}{l}\text { Menyatakan } \\
\text { aliran logika yang } \\
\text { ditunjukan oleh } \\
\text { arah panah }\end{array}$ \\
\hline
\end{tabular}

Sumber : (Kurniadi, 2011)

\section{e. Komponen-Komponen Elektronika}

Menurut Budiharto Widodo (2005: 2) elektronika adalah ilmu yang mempelajari tentang sifat dan pemakaian device yang azas kerjanya berdasarkan aliran elektron didalam ruang hampa atau gas dan aliran elektron serta lubang didalam semikonduktor. Penerapan elektronika mencakup antara lain untuk radio, tv, komputer, instrumen kendali dan peralatan komunikasi lainnya.(Arifin, 2016)

1. LCD $2 \times 16$

Kegunaan Liquid Crystal Display (LCD) banyak sekali dalam perancangan suatu sistem dengan menggunakan mikrokontroler, Liquid Crystal Display ( $L C D$ ) dapat berfungsi untuk menampilkan suatu nilai hasil sensor, menampilkan teks, atau menampilkan menu pada aplikasi mikrokontroler. Modul Liquid Crystal Display (LCD) matrix tersedia dengan konfigurasi 16 karakter dan 2 baris dengan setiap karakternya dibentuk oleh baris pixel. Adapun fitur yang disajikan.(Dinata \& Sunanda, 2015)

2. Sensor Suhu dan Kelembaban DHT 11

DHT11 Sensor ini merupakan sensor dengan kalibrasi sinyal digital yang mampu memberikan informasi suhu dan kelembaban. Sensor ini tergolong komponen yang memiliki tingkat stabilitas yang sangat baik, apalagi digandeng dengan kemampuan mikrokontroler 8 bit seperti Arduino. DHT 11 adalah sensor dengan kualitas terbaik, respon pembacaan yang cepat, dan kemampuan anti interferensi, dengan harga yang sangat terjangkau.(Af'idah, 2014)

\section{Arduino}

Arduino Uno adalah salah satu produk nerlabel Arduino yang sebenarnya adalah suatu papan elektronik yang mengandung mikrokontroler ATmega328 (Sebuah keeping yang secara fungsional bertindak seperti sebuah komputer). Peranti ini dapat dimanfaatkan untuk mewujudkan rangkaian 
IN F O RM A I K A

Jurnal Informatika, Manajemen dan Komputer, Vol. 10, No.1 , MEI 2018

elSSN : 2580 - 3042

pISSN : $1979-0694$

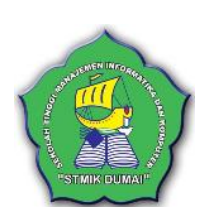

elektronik dari yang sederhana hingga yang kompleks. Arduino Uno mengandung mikroprosesor (berupa Armel AVR) dan dilengkapi dengan oscillator Modul Relay Single Channel $16 \mathrm{MHz}$ (yang memungkinkan operasi berbasis waktu dilaksanakan dengan tepat), dan regulator (pembangkit tegangan) 5 volt.(Ridarmin \& Pandu Pertiwi, 2018)

4. Relay

Relay adalah saklar (Switch) yang dioperasikan secara listrik dan merupakan komponen electromechanical (Elektromekanikal) yang terdiri dari 2 bagian utama yakni Elektromagnet (Coil) dan mekanika ( seperangkat kontak saklar/switch). Fungsi relay pada alat yaitu untuk mengaktifkan dan mematikan elemen pemanas.(Mulyanah \& Hellyana, 2015)

5. Lampu

Lampu pijar adalah sumber cahaya buatan yang dihasilkan dengan penyaluran arus listrik melalui filamen yang kemudian memanas dan menghasilkan cahaya. Kaca yang menyelubungi filamen panas tersebut menghalangi udara untuk berhubungan dengannya sehingga filamen tidak akan langsung rusak akibat teroksidasi. Lampu pijar digunakan karena pancaran cahaya lampu pijar lebih merata dari pada menggunakan heater/pemanas, serta bila dihitung secara ekonomis lampu pijar lebih mudah di dapat dan murah harganya dari pada heaterl pemanas.(Johan, 2016)

\section{METODOLOGI PENELITIAN}

Kerangka Penelitian yang digunakan digunakan dalam penelitian ini adalah sebagai berikut :

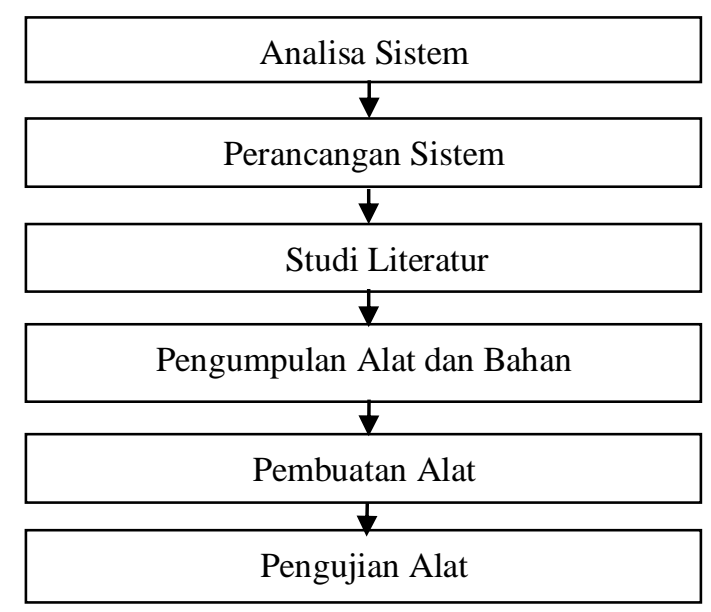

Gambar 1 Kerangka Kerja 
I N F ORM A T I K

Jurnal Informatika, Manajemen dan Komputer, Vol. 10, No.1 , MEl 2018

eISSN : $2580-3042$

pISSN : $1979-0694$

3. HASIL DAN PEMBAHASAN

a. Perancangan Rangkaian Keseluruhan

Alat

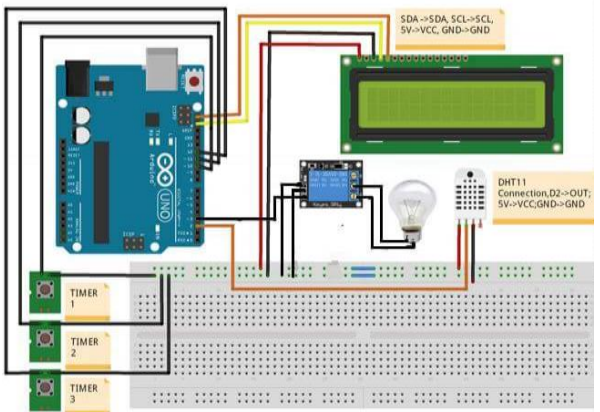

Gambar 2 Perancangan Rangkaian Alat keseluruhan

Gambar diatas merupakan perancangan rangkaian alat pengering pakaian secara keseluruhan. Pada gambar, tampak sambungan antar komponen perangkat keras, yaitu Arduino ke sensor DHT 11, Arduino ke LCD, Arduino ke switch timer, dan Arduino ke relay.

\section{b. Desain Rancangan Alat}

Desain perancangan alat menggambarkan rancangan alat yang sudah dibuat, adapun racangan alat adalah berikut :

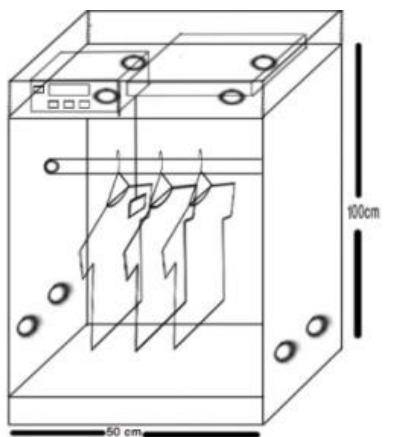

Gambar 3 Desain Rancangan Alat

\section{c. Flowchart Alat Sistem Otomatis}

Agar cara kerja sistem yang dirancang dapat dipahami, maka perlu dibuat pemodelan logika dan algoritma berupa gambar flowchart yang terkandung pada alat pengering pakaian otomatis ini. Gambaran secara singkat proses kerja dimulai dari proses start lalu komponen dan alat dalam keadaan stanby. Kemudian alat dan komponen yang digunakan diset secara keseluruhan. berikutnya proses on pada switch. Lalu terjadi logika if dan batasan kelembapan.dan proses ini terjadi secara terus menerus hingga angka yang ditampilkan di $L C D$ sampai dibatasan logika yang dibuat. Berikut adalah flowchartnya

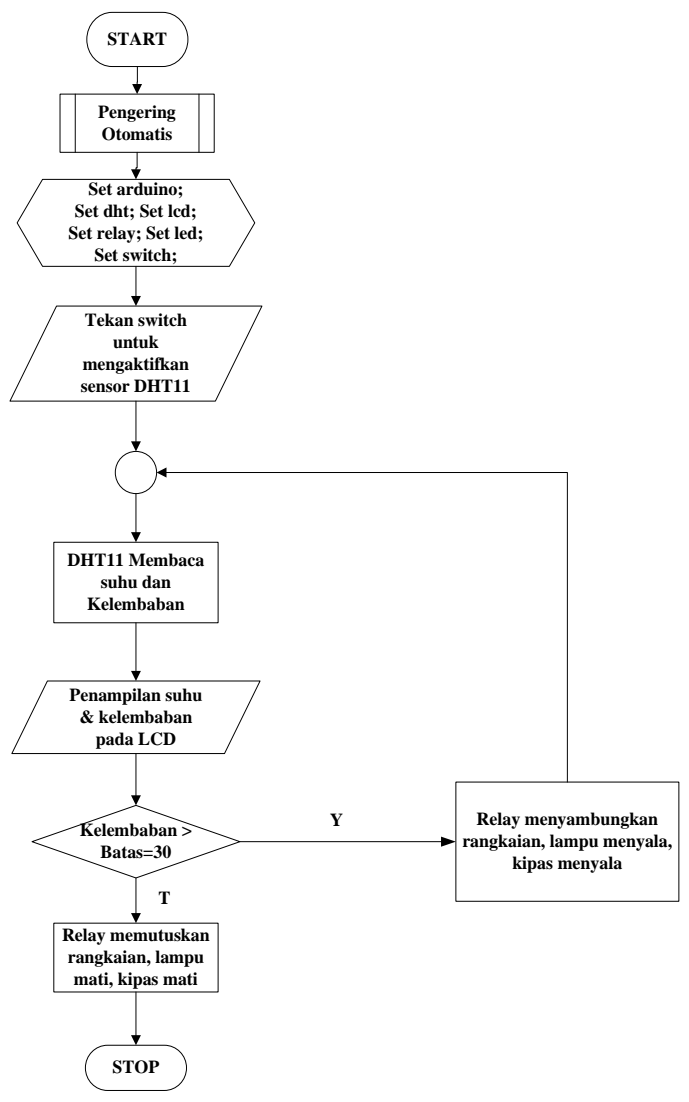

Gambar 4 Flowchart cara kerja alat pengering pakaian otomatis

Tabel 2. Hasil Pengujian Alat Pengering Otomatis

\begin{tabular}{|c|c|}
\hline $\begin{array}{c}\text { Jumlah } \\
\text { Pakaian }\end{array}$ & $\begin{array}{c}\text { Pengeringan } \\
\text { Otomatis }\end{array}$ \\
\hline 1 Pakaian & 17 Menit \\
\hline 2 Pakaian & 28 Menit \\
\hline 3 Pakaian & 47 Menit \\
\hline 4 Pakaian & 58 Menit \\
\hline 5 Pakaian & 1 Jam 20 Menit \\
\hline
\end{tabular}


INFORM T I K A

Jurnal Informatika, Manajemen dan Komputer, Vol. 10, No.1 , MEl 2018

eISSN : $2580-3042$

pISSN : $1979-0694$

Tabel 3. Hasil Waktu Perbandingan Alat Pengering Otomatis dengan Panas Sinar Matahari

\begin{tabular}{|c|c|c|}
\hline $\begin{array}{c}\text { Jumlah } \\
\text { Pakaian }\end{array}$ & $\begin{array}{c}\text { Pengeringan } \\
\text { Otomatis }\end{array}$ & $\begin{array}{c}\text { Panas } \\
\text { Matahari }\end{array}$ \\
\hline 1 Pakaian & 17 Menit & $\begin{array}{c}1 \text { Jam 5 } \\
\text { Menit }\end{array}$ \\
\hline 2 Pakaian & 28 Menit & $\begin{array}{c}1 \text { Jam 28 } \\
\text { Menit }\end{array}$ \\
\hline 3 Pakaian & 47 Menit & $\begin{array}{c}1 \text { jam 20 } \\
\text { menit }\end{array}$ \\
\hline 4 Pakaian & 58 Menit & $\begin{array}{c}1 \text { jam 40 } \\
\text { menit }\end{array}$ \\
\hline 5 Pakaian & 1 Jam 20 Menit & $\begin{array}{c}1 \text { jam 47 } \\
\text { menit }\end{array}$ \\
\hline
\end{tabular}

Kesimpulan dari rincian perbandingan tersebut, jarak waktu pengeringan otomatis dengan panas matahari sekitar 1 jam. Dikarenakan suhu pada lemari lebih stabil/normal dari pada suhu matahari. Oleh karena itu proses pengeringan pada matahari membutuhkan waktu yang relatif lama dari pada proses pengeringan menggunakan lemari.

\section{d. Cara Menggunakan Alat dan Program}

Pada bagian ini akan dijelaskan petunjuk cara menggunakan alat dan mengoperasikan alat yang telah dirancang dengan benar.

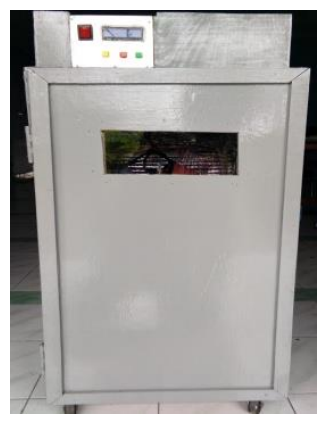

Gambar 5 Tampilan alat pada bagian depan

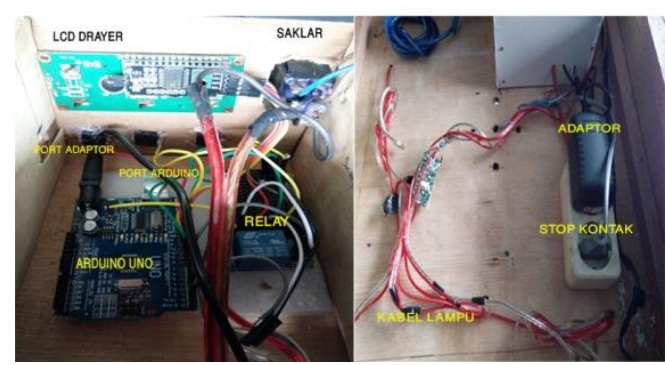

Gambar 6 Tampilan pada bagian atas

1. Langkah pertama dalam penggunaan alat ini, tekan tombol power yang terdapat di tampilan depan lemari, lalu akan muncul nilai suhu dan kelembaban pada $l c d$. Dapat dilihat pada gambar dibawah ini:

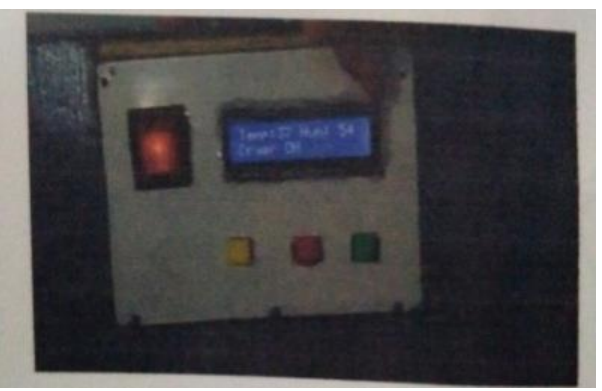

Gambar 7 Hasil Monitoring Kelembaban Dan Suhu Dalam Lemari Pakaian

2. Langakh cara menginput koding ke Arduino, hubungkan kabel USB ke Port USB Arduino, dapat dilihat pada gambar dibawah ini:

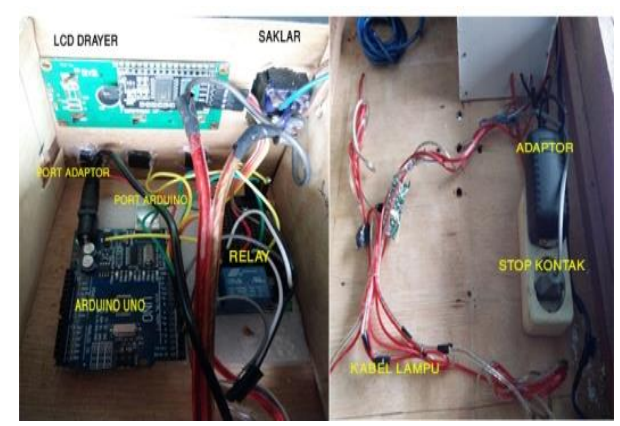

Gambar 8 Kabel USB terhubung dengan port USBRelay dan stop kontak

3. Setelah itu hubungkan ujung kabel $U S B$ Arduino ke laptop. dapat kita lihat pada gambar dibawah ini :

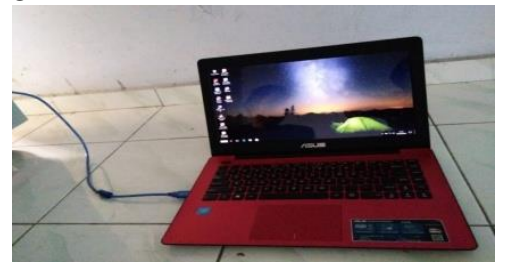

Gambar 9 Laptop terhubung dengan USB Arduino

4. Sebelum menginput, terlebih dahulu kita Compiling listing yang sudah siap untuk di Upload. Jika berhasil akan muncul pemberitahuan (Done Compiling). Baru 
I N F ORM A T I K

Jurnal Informatika, Manajemen dan Komputer, Vol. 10, No.1 , MEI 2018

eISSN : 2580 - 3042

pISSN : $1979-0694$

masuk ke tahap Upload, dapat kita lihat pada gambar dibawah ini:

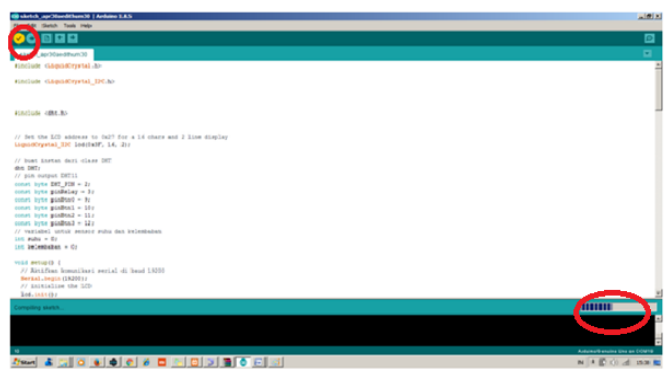

Gambar 10 Proses Compiling Listing

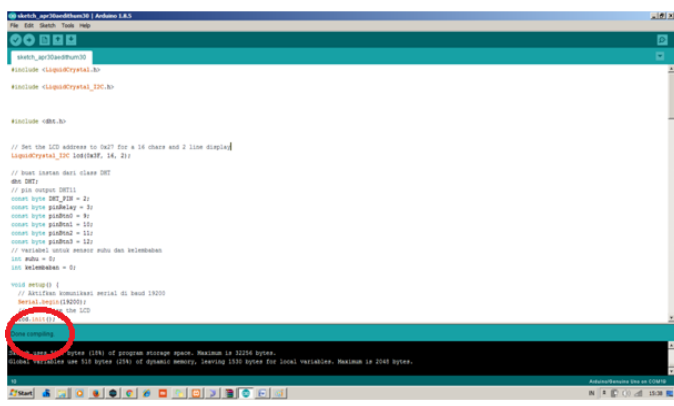

Gambar 11 Proses saat sudah sukses Compiling

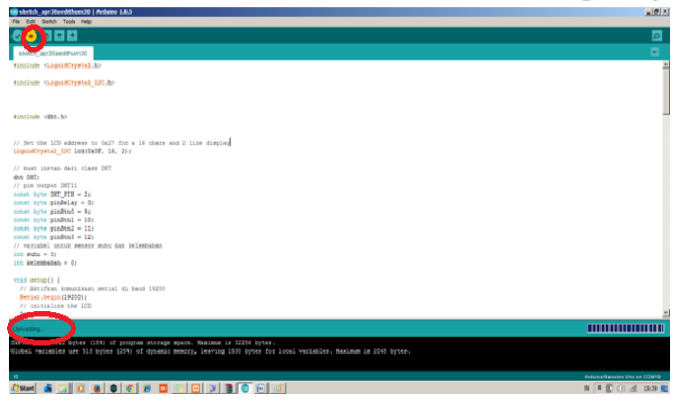

Gambar 9 Proses saat di Upload

\section{KESIMPULAN}

Dengan hasil penelitian tersebut di atas dapat diambil kesimpulan yaitu:

1. Alat mampu mengeringkan 1 pakaian sampai kering dengan waktu 17 menit sedangkan panas sinar matahari dengan waktu 1 jam 5 menit. Sehingga alat ini dapat di gunakan dengan baik.

2. Alat pengering pakaian tersebut akan mati secara otomatis bila pakaian sudah kering.

3. Dapat Membantu para ibu rumah tangga jika sewaktu-waktu hujan, lemari pengering ini bisa menjadi solusi untuk mengeringkan pakaian didalam rumah.

\section{REFERENSI}

Af'idah, D. I. (2014). Perancangan Jaringan Sensor Nirkabel ( Jsn ) Untuk Memantau Suhu Dan Kelembaban Menggunakan Nrf24101 +, 2(4), 267-276.

Arifin, J. N. Z. (2016). Perancangan Murottal Otomatis Menggunakan Mikrokontroller Arduino Mega 2560, 12(1), 89-98.

Dinata, I., \& Sunanda, W. (2015). Implementasi Wirelles Monitoring Energi Listrik Berbasis Web Database, (1), 83-88.

Eka Lestari Kaloko, Z. S. (2016). Persepsi Dan Tingkat Pengetahuan Siswa Tentang Keanekaragaman Hayati Dan Pemanasan Global Di SMA Se-Kecamatan Tigalingga, 4(3), 10-15.

Elisawati. (2017). Sistem Deteksi Objek Dengan Menggunakan Sensor Ultrasonik Berbasis Fuzzy. Jurnal Informatika, Manajemen Dan Komputer, 9(1), 10-14. Retrieved From Http://Www.Ejournal.Stmikdumai.Ac.Id/I ndex.Php/Path/Article/View/58

Johan, A. (2016). Analisis Laju Perpindahan Panas Radiasi Pada Inkubator, 01, 28-36.

Kurniadi, I. (2011). Logika Dan Algoritma Dasar. Jakarta: Mitra Wacana Media. Jakarta.

Kusbianto, D. (2010). Analisis Dan Perancagan Sistem Informasi. STMIK Yadika Bangil.

Mulyanah, E., \& Hellyana, C. M. (2015). Jurnal Evolusi - Volume 3 No 2 -2015 Lppm3.Bsi.Ac.Id/Jurnal, 3(2), 2-6.

Raharjo, B. (2013). Pemograman C++ Mudah Dan Cepat Menjadi Master C++. Bandung: Informatika Bandung.

Ridarmin, \& Pandu Pertiwi, Z. (2018). Prototype Penyiram Tanaman Hias Dengan Soil Moisture Sensor Berbasis Arduino. Jurnal Informatika, Manajemen Dan Komputer, 10(1), 7-11. Retrieved From

Http://Www.Ejournal.Stmikdumai.Ac.Id/I ndex.Php/Path/Article/View/54

Syahwil, M. (2013). Panduan Mudah Simulasi Dan Praktek Mikrokontroler Arduino. (T. A. Prabawati, Ed.). Yogyakarta: Penerbit Andi. 